\title{
ALGEBRAIC PROPERTIES OF THE SET OF OPERATORS WITH 0 IN THE CLOSURE OF THE NUMERICAL RANGE
}

\section{CRISTINA DiOgO}

Abstract. Sets of operators which have zero in the closure of the numerical range are studied. For some particular sets $\mathscr{T} \subseteq \mathscr{B}(\mathscr{H})$, we characterize the set of all operators $A \in \mathscr{B}(\mathscr{H})$ such that $0 \in \overline{W(T A)}$ for every $T \in \mathscr{T}$.

Mathematics subject classification (2010): 47A12.

Keywords and phrases: Numerical range.

\section{REFERENCES}

[1] P. S. BOURDON AND J. H. SHAPIRO, When is zero in the numerical range of a composition operator?, Integr. Equ. Oper. Theory 44 (2002), 410-441.

[2] J. BRAČIČ AND C. DIOGO, Operators with a given part of the numerical range, Math. Slovaca, to appear.

[3] M. Choi And C. Li, Numerical ranges of the powers of an operator, J. Math Anal. Appl. 365 (2010), $458-466$.

[4] H.-L. GAU AND P. Y. WU, Numerical ranges of nilpotent operators, Lin. Alg. Appl. 429 (2008), $716-726$.

[5] K. E. Gustafson And D. K. M. Rao, Numerical Range, Springer-Verlag, New York, 1997.

[6] P. R. Halmos, A Hilbert Space Problem Book, Springer-Verlag, New York, 1982.

[7] J. W. HeLton AND I. M. SpitKovsky, The possible shapes of numerical ranges, Oper. Matrices 6 , 3 (2012), 607-611.

[8] R. A. Horn And C. R. Johnson, Topics in Matrix Analysis, Cambridge University Press, Cambridge, 1985.

[9] S. H. Tso And P. Y. WU, Matricial ranges of quadratic operators, Rocky Mountain J. Math. 29 (1999), 1139-1152. 